\title{
Malathion Biodegradation by L. casei (NRRL1922) and L. acidophilus (NRRL 23431) in Fermented Skimmed Milk
}

\author{
Shaimaa Basyouni Hassan El-Abd ${ }^{1 *}$ (D), Hala Mohamed Abu-Shady², \\ Hosam Abdel Fattah Mohamed Elshebiny', Mohamed Abdel-Azim \\ Abdel-Aziz Ebrahim $^{1}$ (D) and Hayam Abdelnabi Sayed ${ }^{2}$ (D) \\ ${ }^{1}$ Poison Control Center, Ain Shams University, Hospitals, Cairo - 11566, Egypt. \\ ${ }^{2}$ Microbiology Department, Faculty of Science, Ain Shams University, Cairo - 11566, Egypt.
}

\begin{abstract}
The aim of this study was to investigate and trace the biodegradation products of the pesticide malathion in a comparative manner by two different lactobacilli strains; $L$. casei (NRRL1922) and $L$. acidophilus (NRRL 23431). The two strains were cultivated separately into skimmed milk supplemented with $5 \mathrm{ng} / \mathrm{ml}$ malathion. After incubation under the appropriate conditions, randomized samples were taken at intervals 24, 48, 72 and 120 hours along with control samples and analyzed for the presence of malathion and its degradation products by the GC-MS spectrometry; As well as, analyzed to record the level of phosphatase enzyme which suggested to be involved in the biodegradation process. The results showed a high ability of the two tested strains to degrade malathion with a superiority of $L$. acidophilus (NRRL 23431) over $L$. casei (NRRL 1922). The level of phosphatase enzyme was elevated in both strains in the presence of malathion and decreased gradually upon the depletion of malathion from the sample, which reflects the role of the phosphatase enzyme in the biodegradation process.

Keywords: Malathion, Biodegradation, Lactic acid bacteria, Metabolites
\end{abstract}

*Correspondence: shaimaa.elabd.86@gmail.com

(Received: June 24, 2021; accepted: August 07, 2021)

Citation: El-Abd SBH, Abu-Shady HM, Elshebiny HAFM, Ebrahim MAA, Sayed HA. Malathion Biodegradation by L. casei (NRRL1922) and L. acidophilus (NRRL 23431) in Fermented Skimmed Milk. J Pure Appl Microbiol. 2021;15(3):1617-1624. doi: 10.22207/JPAM.15.3.58

(c) The Author(s) 2021. Open Access. This article is distributed under the terms of the Creative Commons Attribution 4.0 International License which permits unrestricted use, sharing, distribution, and reproduction in any medium, provided you give appropriate credit to the original author(s) and the source, provide a link to the Creative Commons license, and indicate if changes were made. 


\section{INTRODUCTION}

Organophosphorus has been widely used for eradicating pests. However, they are highly toxic to human health and cause serious public problems that are reported in many studies $^{1-9}$. The OPPs are all esters of phosphoric acid which include aliphatic, phenyl and heterocyclic derivatives. So, most of organophosphorus can be used by microorganisms as carbon and/ or phosphate source in the environment by carboxylesterase and phosphatase activities ${ }^{10,11}$.

Malathion is wide-spectrum pesticide. It is widely used worldwide for agricultural, residential, and public health purposes, primarily to improve food production and provide protection against disease vectors. It has a major importance in Egypt due to its wide distribution, persistence and extensive use. Malathion led to contamination of soil, air, surface and groundwater.

Milk is an ideal fluid for dissolving environmental organic pollutants such as pesticide residues because most of them have lipophilic properties. Thus, milk is used as an indicator for determining the persistence of organic pollutants ${ }^{12}$. Their presence in dairy products occurs mostly due to the feeding of contaminated fodder, feedstuff and water to dairy cattle ${ }^{13}$.

Technical-grade malathion which is usually used for agricultural purposes may contain up to 11 impurities formed during its production and/or storage, many of these impurities, such as isomalathion and malaoxon that have been found to be significantly more toxic than malathion itself or to potentiate malathion toxicity ${ }^{14}$.

Biodegradation of pesticides by microorganisms is safer and cheaper than other ways to reduce pesticides level especially in the processed milk. But, the most crucial point is the type of the microorganism that can biodegrade the contaminant and being itself safe. Also, the biodegradation process that may resulted in products that may be toxic than the parent compound ${ }^{15}$

There are different genera have been used in the bioremediation of organophosphorus pesticides in the polluted environment including Pseudomonas ${ }^{16}$ and Paracoccus ${ }^{17}$. For the sake of food safety guidelines many researches began to investigate the ability of Lactic acid bacteria - generally regarded as safe bacteria- to degrade toxic substances in raw food products or during manufacturing process ${ }^{18}$. Probiotic Lactic acid bacteria may be potential microbes for reducing the risk of pesticides in food and environment ${ }^{19}$. Unlikely, only very few reports have investigated the degradation of organophosphorus contaminant by microorganisms in food matrices ${ }^{20}$.

Previous studies have studied LAB for the degradation of malathion for example, Zhang et $a^{21}$ assayed quantitatively the degradation of five organophosphorus including malathion in skimmed milk at $42^{\circ} \mathrm{C}$ by ten different species of lactic acid bacteria. Also, the phosphatase excreted by these microorganisms in the milk was also measured. Also, Zhou \& Zhao ${ }^{22}$ investigated different strains of lactic acid bacteria and yogurt starters that enhance the biodegradation of nine organophosphorus in skimmed milk and analyzed phosphatase enzyme activity. In this study, two different strains of lactic acid bacteria $L$. casei (NRRL 1922) and L. acidophilus (NRRL 23431) were investigated for malathion biodegradation by tracking its secondary metabolites during different intervals $24,48,72,120$ hours by GC-MS to evaluate precisely the degradation ability of the two strains along with the phosphatase enzyme activity excreted by these two strains in the same intervals. To the best of our knowledge, this is the first study to track the secondary metabolites of malathion with two different strains of lactic acid bacteria.

\section{MATERIALS AND METHODS}

Malathion utilized in this study was obtained from Kafr Elzayyat company, Egypt (95\% active ingredient).

Two LAB strains L. casei (NRRL1922) -referred as (L1)- and L. acidophilus (NRRL 23431) - referred as (L2), were obtained in lyophilized form from the ARS Culture Collection (The National Center for Agricultural Utilization Research in Peoria, Illinois). Skimmed milk powder was obtained from a local market and stored at $4^{\circ} \mathrm{C}$ before use. All chemical reagents used were analytical grade, while solvent used were highperformance liquid chromatography-grade.

\section{Strain activation}

The two LAB strains were rehydrated in $1.0 \mathrm{~mL}$ sterilized skimmed milk medium (11g skimmed milk. $100 \mathrm{ml} \mathrm{d.} \mathrm{H}_{2} \mathrm{O}$ ) then cultivated into 
a normal MRS broth medium, (Oxoid Ltd., England) $(5 \%, v / v)$ and cultured at $37^{\circ} \mathrm{C}$ for $24 \mathrm{~h}$. The MRS medium re-culturing was repeated four times to ensure the full viability and purity of the strains ${ }^{21,22}$.

Then, the strains were sub-cultured in a skimmed milk medium of $11 \%(\mathrm{w} / \mathrm{w})$ for $12 \mathrm{~h}$ before use as the biodegradability experiment will be carried out in the skimmed milk as a medium. Milk sample preparation and inoculation

Malathion was added into the skimmed milk $(11 \%, w / w)$ at $5 \mathrm{ng} / \mathrm{ml}$ and stirred for enough time at room temperature to ensure well distribution of malathion. After sterilization of the spiked skimmed milk at the appropriate sterilization program $\left(90^{\circ} \mathrm{C}\right.$ for $\left.15 \mathrm{~min}\right)$ and cooling to room temperature; LAB starters (L1 and L2) were inoculated separately into the treated milk at a level of $5 \%(\mathrm{v} / \mathrm{v})$. The samples along with the control (malathion treated milk without inoculation of bacteria) were incubated at $37^{\circ} \mathrm{C}$. for $24,48,72$ and 120 hours, respectively; Some samples were selected randomly for analysis along with control samples at each interval time ${ }^{21,22}$.

\section{Extraction and purification of organophosphorus pesticides}

The OPPs extraction and purification from milk samples were carried out three times. The process carried out by the addition equal volume of a $1: 4, v / v$ acetone-acetonitrile mixture to 10 $\mathrm{ml}$ sample with hard shaking for a while then the samples were centrifuged for $400 \times \mathrm{g}$ for $6 \mathrm{~min}$. The collected upper liquid phases -containing the malathion- after the three times of extraction was transferred to a separation funnel for the purification with $50 \mathrm{ml}$ dichloromethane with shaking for $\mathbf{2 0}$ minutes, then left enough time for phase separation. As a final step in purification and cleaning up process. The dichloromethane phase was separated, and filtered through anhydrous sodium sulphate ( $2 \mathrm{gm}$ ) for dehydrating the sample and collected as a purified pesticide extract. Pagliuca et al $23 \mathrm{~A} 15.0 \mathrm{ml}$ sample of the purified extract was evaporated to dryness at $30^{\circ} \mathrm{C}$ with nitrogen gas in an evaporation station. The residue was reconstituted to a volume of 1.0 $\mathrm{mL}$ with acetone and filtered through a $0.45 \mu \mathrm{m}$ microporous membrane filter to get rid of any impurities including bacterial cell before GC-MS analysis ${ }^{24}$.

\section{GC-MS analysis}

For GC-MS analysis, $150 \mathrm{ml}$ sample from the purified extract was evaporated to dryness. The residue was re-dissolved in $1 \mathrm{ml}$ acetone and filtrated by syringe filter $0.45 \mu \mathrm{m}$ to remove any present impurities; thereafter $200 \mu \mathrm{l}$ from it injected into the GLC system. Gas chromatographic analyses were carried out using Trace GC UltraTSQ Quantum mass spectrometer (Thermo Scientific, Austin, TX, USA) with a direct capillary column TG-5MS (30 m x $0.25 \mathrm{~mm} \times 0.25 \mu \mathrm{m}$ film thickness). The temperature of the column oven was held initially at $70^{\circ} \mathrm{C}$ hold for $5 \mathrm{~min}$ and then increased by $5^{\circ} \mathrm{C} / \mathrm{min}$ to $280^{\circ} \mathrm{C}$ hold for $5 \mathrm{~min}$. Temperature of the injector and MS transfer line were held at $250^{\circ} \mathrm{C}$. Helium was used as a carrier gas at a constant rate of flow rate of $1 \mathrm{ml} / \mathrm{min}$. The delay of the solvent was $4 \mathrm{~min}$ and $3 \mu \mathrm{l}$ of diluted samples were automatically injected using Autosampler AS1310 coupled with GC in the split mode. The GC-MS was operated in a SIM/SCAN Mode 25 .

\section{Assay of phosphatase activity}

The selected samples for malathion analysis were used for studying phosphatase activity along with malathion degradation in addition to three sets of control: the first set contains malathion only, the second one contains the tested bacteria L1 only, and the third set contains the tested bacteria L2 only. The samples as well as the controls were centrifuged $10,000 \times$ $\mathrm{g}$ for 15 minutes at $4^{\circ} \mathrm{C}$, the harvested bacterial cells were washed three times by $10 \mathrm{mmol} \mathrm{L}^{-1}$ sodium carbonate/bicarbonate buffer (which was prepared by dissolving $3.5 \mathrm{gm}$ of anhydrous sodium carbonate and $1.5 \mathrm{gm}$ of sodium bicarbonate in one liter of distilled water, $\mathrm{pH} 10.5$ ). The harvested, washed bacterial cells were resuspended in $5 \mathrm{~mL}$ of $10 \mathrm{mmol} \mathrm{L}^{-1}$ sodium carbonate/bicarbonate buffer and agitated for 1 minute. The cells mixed with the buffer subjected to sonication for 10 seconds ten times with 15 seconds intervals to set the phosphatase enzyme free outside the bacterial cells; then the samples were centrifuged to get rid of the cell debris. The supernatant of each sample was used to evaluate the phosphatase activity separately. The phosphatase activity was measured according to Zhou \& Zhao ${ }^{22}$.

The level of serum alkaline phosphatase (ALP) was assayed by quantitative kinetic assay 
Table 1. The relative abundance of Malathion and its metabolites fragment ions in L1 treatment

\begin{tabular}{|c|c|c|c|c|c|c|}
\hline \multirow{3}{*}{$\begin{array}{l}\text { MF and MW of } \\
\text { different fragments }\end{array}$} & \multicolumn{6}{|c|}{ Relative abundance of fragment ions at different intervals (\%) } \\
\hline & \multicolumn{2}{|c|}{24 hours } & \multirow{2}{*}{$\begin{array}{l}48 \\
\text { L1 }\end{array}$} & \multirow{2}{*}{$\begin{array}{l}72 \\
\text { L1 }\end{array}$} & \multicolumn{2}{|c|}{120} \\
\hline & Control & L1 & & & Control & L1 \\
\hline $\begin{array}{l}\text { Malathion } \\
\text { MF: } \mathrm{C}_{10} \mathrm{H}_{19} \mathrm{O}_{6} \mathrm{PS}_{2} \\
\text { MW: } 330.4 \mathrm{~g} / \mathrm{mol}\end{array}$ & 42.89 & 30.14 & 15.14 & 3.99 & 23.89 & 0.95 \\
\hline $\begin{array}{l}\text { Malaoxon } \\
\text { MF: } \mathrm{C}_{10} \mathrm{H}_{19} \mathrm{O}_{7} \mathrm{PS} \\
\text { MW: } 314.29 \mathrm{~g} / \mathrm{mol}\end{array}$ & 22.02 & 11.68 & 8.22 & 3.23 & 42.02 & 0.45 \\
\hline $\begin{array}{l}\text { Isomalathion } \\
\text { MF: } \mathrm{C}_{10} \mathrm{H}_{19} \mathrm{O}_{6} \mathrm{PS}_{2} \\
\mathrm{MW}: 330.4 \mathrm{~g} / \mathrm{mol}\end{array}$ & 11.56 & 5.22 & 3.55 & 1.89 & 29.56 & 1.0 \\
\hline $\begin{array}{l}\text { 2_mercaptosuccinic acid } \\
\mathrm{MF}: \mathrm{C}_{4} \mathrm{H}_{6} \mathrm{O}_{4} \mathrm{~S} \\
\mathrm{MW}: 150.16 \mathrm{~g} / \mathrm{mol}\end{array}$ & & 15.22 & 12.22 & 5.53 & & 1.53 \\
\hline $\begin{array}{l}\text { malathion monocarboxylic } \\
\text { acid (MMA) }\end{array}$ & & 30.24 & 31.65 & 32.05 & & 36.12 \\
\hline $\begin{array}{l}\text { MF: } \mathrm{C}_{8} \mathrm{H}_{15} \mathrm{O}_{6} \mathrm{PS}_{2} \\
\mathrm{MW}: 302.3 \mathrm{~g} / \mathrm{mol} \\
\text { malathion dicarboxylic } \\
\text { acid (MDA) } \\
\text { MF: } \mathrm{C}_{6} \mathrm{H}_{11} \mathrm{O}_{6} \mathrm{PS}_{2} \\
\mathrm{MW}: 274.3 \mathrm{~g} / \mathrm{mol}\end{array}$ & & 12.33 & 15.89 & 17.88 & & 25.66 \\
\hline
\end{tabular}

method using alkaline phosphatase kit (214001, Spectrum, Obour city, Cairo, Egypt) following the manufacturer's instructions by preparing the working solution according to the number of tests required by mixing 9 volumes of buffer solution (R1) which contain 2-Amino-2-Methyl-1-Propanol ( $\mathrm{pH} 10.3$ ) and $\mathrm{MgCl}_{2}$ and 1 volume of substrate (R2) which contain p-Nitrophenylphosphate, e.g. $900 \mu \mathrm{l} 1+100 \mu \mathrm{l} 22$ then a volume of $10 \mu \mathrm{l}$ of the sample was added to $1 \mathrm{ml}$ of the working solution, mixed carefully and read initial absorbance in a photometer DTN-405 Semi - automated chemistry analyzer (Austrian) at $405 \mathrm{~nm}$ after 1 minute and start timer simultaneously. Read again after 1, 2 and 3 minutes. Determine the mean absorbance change per minute $(\Delta \mathrm{A} / \mathrm{min})$.

\section{Calculation $\Delta$}

$\operatorname{ALP}$ activity $(\mathrm{U} / \mathrm{L})=\Delta \mathrm{A} 405 \mathrm{~nm} / \mathrm{min} \times 5454$ Where $(\Delta \mathrm{A} / \mathrm{min})$ is the average of the readings.

\section{RESULTS}

Investigation of malathion biodegradation by GC-MS

Data in Table 1, 2 showed considerable decrease in the relative abundance of malathion fragment ions after incubation with $\mathrm{L} 1$ and $\mathrm{L} 2$ strains over elapsed time. Data revealed that $\mathrm{L} 2$ treatment decreased the relative abundance of malathion fragment ions over L1 treatment.

The separation of the degraded products by GC-MS in control samples ( $95 \%$ purity) showed the appearance of the molecular ion peak of malaoxon fragment ions and the molecular ion peak of isomalathion fragment ions (which formed normally upon storage). The relative abundance of malaoxon and isomalathion fragment ions were decreased in spiked milk as the culture time progressed in L1 treatment until it reach its lowest level in the 5 th day by $1.0,0.45$ respectively when compared to control. Also, in L2 treatment the 
Hassan El-Abd et al. | J Pure Appl Microbiol | 15(3):1617-1624 | September 2021 | https://doi.org/10.22207/JPAM.15.3.58

Table 2. The relative abundance of Malathion and its metabolites fragment ions in L2 treatment

\begin{tabular}{|c|c|c|c|c|c|c|}
\hline \multirow{3}{*}{$\begin{array}{l}\text { Fragment Chemical } \\
\text { formula and Molecular } \\
\text { wight } \\
\text { Relative abundance of } \\
\text { fragment ions\% in } \\
\text { different hours }\end{array}$} & \multicolumn{6}{|c|}{ Relative abundance of fragment ions at different intervals (\%) } \\
\hline & \multicolumn{2}{|c|}{24 hours } & \multirow[t]{2}{*}{48 hours } & \multirow[t]{2}{*}{72 hours } & \multicolumn{2}{|c|}{120 hours } \\
\hline & control & L2 sample & & & Control & L2 sample \\
\hline $\begin{array}{l}\text { Malathion } \\
\mathrm{C}_{10} \mathrm{H}_{19} \mathrm{O}_{6} \mathrm{PS}_{2} \\
\text { M.wt } 330\end{array}$ & 42.89 & 15.14 & 10.22 & 6.55 & 23.89 & 2.76 \\
\hline $\begin{array}{l}\text { Malaoxon } \\
\mathrm{C}_{10} \mathrm{H}_{19} \mathrm{O}_{7} \mathrm{PS} \\
\text { M.wt } 314\end{array}$ & 22.02 & 15.55 & 12.24 & 8.13 & 42.02 & 2.18 \\
\hline $\begin{array}{l}\text { Isomalathion } \\
\mathrm{C}_{10} \mathrm{H}_{19} \mathrm{O}_{7} \mathrm{PS} \\
\text { M.wt } 314\end{array}$ & 11.56 & 3.22 & 2.05 & 1.22 & 29.56 & 0.85 \\
\hline $\begin{array}{l}\text { 2-mercaptosuccinic acid } \\
\mathrm{C}_{4} \mathrm{H}_{6} \mathrm{O}_{4} \mathrm{~S} \\
\text { M.wt } 150\end{array}$ & & 9.55 & 7.22 & 4.05 & & 1.11 \\
\hline $\begin{array}{l}\text { malathion monocarboxylic } \\
\text { acid (MMA) } \\
\mathrm{C}_{10} \mathrm{H}_{19} \mathrm{O}_{7} \mathrm{PS} \\
\text { M.wt } 314\end{array}$ & & 45.24 & 52.21 & 60.24 & & 68.66 \\
\hline $\begin{array}{l}\text { malathion dicarboxylic } \\
\text { acid (MDA) } \\
\mathrm{C}_{6} \mathrm{H}_{11} \mathrm{O}_{6} \mathrm{PS} \\
\text { M.wt } 274\end{array}$ & & 10.23 & 15.44 & 19.42 & & 23.52 \\
\hline
\end{tabular}

relative abundance of malaoxon, isomalathion fragment ions decreased at $1^{\text {st }}, 2^{\text {nd }}$ and $3^{\text {rd }}$ of incubation period until it reach the $5^{\text {th }}$ day by 2.18 , 0.85 respectively when compared to control due to the biodegradation process.

After the first 24 hours in L1 and L2 treatment, the molecular ion peak of malathion monocarboxylic acid (MMA) and malathion dicarboxylic acid (MDA) were detected. In L1 and L2 treatment, the relative abundance of MMA and MDA fragment ions were increased in spiked milk with malathion being decreased and it continued increasing until they reached their highest level in the 5th day of incubation period by 36.12 and 25.66 in L1 treatment and 68.66 and 23.52 in L2 treatment respectively. These data indicated that the main products resulted from bacterial biodegradation is malathion monocarboxylic acid which may convert to malathion dicarboxylic acid over time.
Also, the molecular ion peak of the low molecular weight 2-mercaptosuccinic acid fragment ions was detected which was reported as an environmental transformation product of malathion ${ }^{26}$. The relative abundance of 2-mercaptosuccinic acid fragment ions was decreased upon the $\mathrm{L} 1$ and $\mathrm{L} 2$ treatment over elapsed time as demonstrated in Table 1 and Table 2.

Determination of phosphatase enzyme activity

Malathion biodegradation to malathion monocarboxylic acid and malathion dicarboxylic acid may occur through the action of phosphatase enzyme. Phosphates activity was measured by using kinetic method over the intervals of incubation 24, 48, 72 and 120 hours; Results showed that phosphatase activity increased with increasing the incubation period as shown in Table 3, which indicate the continuous increase in phosphatase activity in skimmed milk in the 
Table 3. The level of phosphatase enzyme activity (U/L)

\begin{tabular}{lccccc}
\hline $\begin{array}{l}\text { Incubation } \\
\text { period (hours) }\end{array}$ & A & B & C & D & E \\
\hline 24 & 0 & 8 & 78 & 16 & 170 \\
48 & 0 & 12 & 106 & 45 & 200 \\
72 & 0 & 20 & 170 & 56 & 215 \\
120 & 0 & 23 & 185 & 75 & 220 \\
\hline
\end{tabular}

(A): Phosphatase enzyme activity in malathion only group., (B): Phosphatase enzyme activity in L1 only.,

(C): Phosphatase enzyme activity in spiked milk with malathion inoculated with L1.

(D): Phosphatase enzyme activity in L2 only.,

(E): Phosphatase enzyme activity in spiked milk with malathion inoculated with $\mathrm{L} 2$.

presence of malathion and reflects its main role in malathion biodegradation. Generally, L2 produced higher levels of phosphatase enzyme in comparison with L1 whether in the presence or absence of malathion.

\section{DISCUSSION}

Due to the importance of milk in the diet of infants, children and also adults, the presence of significant amounts of residues is undesirable ${ }^{27}$. Consequently, residues limit for milk and dairy products tend to be more severe than those for other food stuffs. The annual reports of the WHO and FAO committee group represents tolerance level and limits for individual pesticides in different food commodities including milk and dairy products ${ }^{28}$.

In the present study, the efficiency of two LAB strains L. casei 1922 (L1) L. acidophilus 23431 (L2), on the biodegradation of malathion in skimmed milk was investigated.

In the current study the two tested strain showed their ability to degrade malathion in skimmed milk. For L1, the malathion ion fragment was decreased in a nearly steady gradual rate as it decreased by about 30\%, 65\%, 91\% and 97\% over the different incubation periods respectively, while in case of $L 2$, the degradation rate pattern was different where at the first 24 and 48 hours the degradation rate was higher than in L1 as the malathion ion decreased by $65 \%$, and $74 \%$ respectively, then over the third and the fifth days the degradation rate was less than that of $L 1$, it was about $85 \%$ and $88 \%$ respectively. The ability of the tested two strains in this study to degrade
OPPs including malathion was reported by Zhou \& Zhao ${ }^{22}$. Also, the biodegradation of different OPPs including malathion during yoghurt processing (milk fermentation) by lactic acid bacteria was recorded by Bo \& $\mathrm{ZhaO}^{24}$. Also, biodegradation of malathion by Zhang et $\mathrm{al}^{21}$ was investigated by different species of lactic acid bacteria.

The GC-MS analysis showed that Malathion and its two enantiomers breached forming 2-mercaptosuccinic acid and malathion mono- and di-succinic acids (The possible pathway for malathion biodegradation by microorganisms); These finding of metabolic products were reported by many studies ${ }^{29-31}$. In these studies they demonstrated the degradation of malathion into malathion monocarboxylic acid which partially transformed to malathion dicarboxylic acid and gradually to various phosphothionates by the action of some bacterial strains upon increasing incubation time.

The decrease in the degradation rate by L2 in the third and the fifth day may be due to the accumulation of the degradation metabolites malathion mono and di-malathion succinic acids which may confer the feedback effect on the substrate breakdown. Anyway; the ability of L2 in the biodegradation was higher than that of $L 1$, this was concluded from the area percent of the metabolites in the analyzed samples where the final relative abundance of malathion monosuccinic acid which is the first degradation product of malathion after 120 hours incubation in L2 treated samples were more than that in L1 treated samples by about $53 \%$, as well as the malathion di-succinic acid. Although L1 showed higher activity on the enantiomer malaoxon producing 2-mercaptosuccinate than L1 as shown in Table 1 and 2, it was clear from the final concentration of this compound upon the fifth day that $L 2$ have a greater ability for further transformation of 2-mercaptosuccinate into other degradation products. But theses finding conflict those of Zhou \& $\mathrm{ZhaO}^{22}$, as they reported in their study that $L$. casei have a little less ability to degrade malathion than $L$. acidophilus. This conflict may come from the time in the current study was about five days. on the other hand, in Zhou \& Zhao, malathion was investigated in 24 hours only.

Anyway, in this study these finding were enhanced by the phosphatase level in the two 
tested strains; where it was found that $\mathrm{L} 2$ has a higher enzyme level during all the incubation periods which explain the higher activity of L2 in the biodegradation process of the tested OPP malathion as well as its enantiomers. Where, many studies related the level of phosphatase enzyme with the ability of OPPs degradation ${ }^{15,32,21}$.

\section{CONCLUSION}

Many Probiotic may have the ability to rescue our health from OPPs toxicity; so, different probiotics could be investigated for OPPs degradation ability in different food materials to reduce the toxicity risk of these harmful pesticides. Whole bacterial cells or their enzymes could be applicable. Also, probiotics which can degrade OPPs may play a role in our bodies if administrated regularly in reducing the effect of these pesticides, so in vivo studies are required. To the best of our knowledge, this the first study to track malathion metabolites with two different strains of lactic acid bacteria by GC-MS.

\section{ACKNOWLEDGMENTS}

The authors are greatly thankful to the Department of Microbiology, Faculty of Science, Ain Shams University, Egypt.

\section{CONFLICT OF INTEREST}

The authors declare that there is no conflict of interest.

\section{AUTHORS' CONTRIBUTION}

HA conceived and designed the work. HAF collected the data. MAAE did the data analysis and interpretation. HAS critically revised the article

\section{FUNDING}

None.

\section{DATA AVAILABILITY}

All datasets generated or analyzed during this study are included in the manuscript

\section{ETHICS STATEMENT}

This article does not contain any studies with human participants or animals performed by any of the authors.

\section{REFERENCES}

1. Ragnarsdottir KV. Environmental fate and toxicology of organophosphate pesticides. Journal of the Geological Society.2000; 157(4), 859-876. doi: 10.1144/jgs.157.4.859

2. Singh R. Biodegradation of xenobiotics-a way for environmental detoxification. Int I Dev Res. 2017;7(7):14082-14087.

3. Yair S, Ofer B, Arik E, et al. Organophosphate 361 degrading microorganisms and enzymes as biocatalysts in environmental and personal decontamination applications. Crit Rev Biotechnol. 2008;28(4):265- 275. doi:10.1080/07388550802455742.

4. Colosio C, Tiramani M, Brambilla G, Colombi A, Moretto A. Neurobehavioural effects of pesticides with special focus on organophosphorus compounds: which is the real size of the problem? Neurotoxicology. 2009;30(6):1155-1161. doi: 10.1016/j.neuro.2009.09.001.

5. Jokanovic $M$, Prostran $M$. Pyridinium oximes as cholinesterase reactivators. Structure- activity relationship and efficacy in the treatment of poisoning with organophosphorus compounds. Curr Med Chem. 2009;16(17):2177-2188. doi: 10.2174/092986709788612729.

6. Tchounwou PB, Patlolla AK, Yedjou CG, Moore PD. Environmental exposure and health effects associated with Malathion toxicity. Toxicity and Hazard of Agrochemicals. 2015;51:2145-2149. doi: 10.5772/60911

7. Karami-Mohajeri S, Ahmadipour A, Rahimi HR, Abdollahi M. Adverse effects of organophosphorus pesticides on the liver: a brief summary of four decades of research. Arh Hig Rada Toksikol. 2017;68(4):261275. doi: 10.1515/aint-2017-68-2989

8. Yan J, Xiang B, Wang D, et al. Different Toxic Effects of Racemate, Enantiomers, and Metabolite of Malathion on HepG2 Cells Using High-Performance Liquid Chromatography-Quadrupole-Time-of-Flight-Based Metabolomics. J Agri Food Chem. 2019;67(7):17841794. doi: 10.1021/acs.jafc.8b04536

9. Abdel-Daim MM, Abushouk Al, Bungau SG, et al. Protective effects of thymoquinone and diallyl sulphide against malathion-induced toxicity in rats. Environ $\mathrm{Sci}$ Pollut Res. 2020;27(10):10228-10235. doi: 10.1007/ s11356-019-07580-y

10. Stoytcheva M. Pesticides in the Modern World: Pesticides Use and Management. BoD- Books on Demand; 2011. doi: 10.5772/950

11. Kumral A, Kumral NA, Gurbuz O. Chlorpyrifos and deltamethrin degradation potentials of two Lactobacillus plantarum (Orla-Jensen, 1919) (Lactobacillales: Lactobacillaceae) strains. Turkiye Entomoloji Dergisi. 2020;44(2):165-176. doi: 10.16970/ entoted.625156

12. Nasef IO, El-Leboudy AA, Amer AA, El-Ansary MA. Monitoring of some pesticides residues in raw milk in Alexandria province, Egypt. Alexandria Journal of Veterinary Sciences. 2019;60(1):196-203. doi: 10.5455/ ajvs.1373 
13. Wochner KF, Becker-Algeri TA, Colla E, BadialeFurlong $E$, Drunkler DA. The action of probiotic microorganisms on chemical contaminants in milk. Crit Rev Microbiol. 2018;44(1):112-123. doi: 10.1080/1040841X.2017.1329275

14. Konrad, JG, Chesters G, Armstrong DE. Soil degradation of malathion, a phosphorodithioate insecticide. Soil Science Society of America Journal. 1969; 33(2), pp.259262. doi:10.2136/sssaj1969.03615995003300020026x

15. Huang Y, Xiao L, Li F, et al. Microbial degradation of pesticide residues and an emphasis on the degradation of cypermethrin and 3-phenoxy benzoic acid: A review. Molecules. 2018;23(9):2313. doi: 10.3390/ molecules23092313

16. Li-feng G, Jian-dong J, Xiao-hui L, Ali SW, Shun-pengv L. Biodegradation of ethametsulfuron-methyl by Pseudomonas sp. SW4 isolated from contaminated soil. Curr Microbiol. 2007;55(5):420-426. doi: 10.1007/ s00284-007-9011-x

17. Jing-Liang $X U$, Jun WU, Zhi-Chun WANG, et al. Isolation and characterization of a methomyl-degrading Paracoccus sp. mdw-1. Pedosphere, 2009; 19(2), 238243.

18. Regueiro J, Lopez-Fernandez O, Rial-Otero R, Cancho-Grande B, Simal-Gandara J. A review on the fermentation of foods and the residues of pesticides-biotransformation of pesticides and effects on fermentation and food quality. Crit Rev Food Sci Nutr. 2015;55(6):839-863. doi: 10.1080/10408398.2012.677872

19. Trinder M, Bisanz JE, Burton JP, Reid G. Probiotic lactobacilli: a potential prophylactic treatment for reducing pesticide absorption in humans and wildlife. Benef Microbes. 2015;6(6):841-847. doi: 10.3920/ BM2015.0022.

20. Li C, Ma Y, Mi Z, et al. Screening for Lactobacillus plantarum strains that possess organophosphorus pesticide-degrading activity and metabolomic analysis of phorate degradation. Front Microbiol. 2018;9:2048. doi: 10.3389/fmicb.2018.02048

21. Zhang YH, Xu D, Liu JQ, Zhao XH. Enhanced degradation of five organophosphorus pesticides in skimmed milk by lactic acid bacteria and its potential relationship with phosphatase production. Food Chemistry. 2014;164:173-178. doi: 10.1016/j. foodchem.2014.05.059

22. Zhou XW, Zhao XH. Susceptibility of nine organophosphorus pesticides in skimmed milk towards inoculated lactic acid bacteria and yogurt starters. J SCi Food Agri. 2015;95(2):260-266. doi: 10.1002/jsfa.6710

23. Pagliuca G, Serraino A, Gazzotti T, Zironi E, Borsari A, Rosmini R. Organophosphorus pesticides residues in Italian raw milk. J Dairy Res. 2006;73(3):340-344. doi: 10.1017/S0022029906001695

24. Bo L, Zhao X. Degradation kinetics of seven organophosphorus pesticides in yoghurt and cheese in yoghurt and cheese during fermentation. China Dairy Industry. 2010;38(8):22-25

25. El-Fiki A, Adly M. Morphological, molecular, and organosulphur compounds characterization in irradiated garlic (Allium sativum) by GC-MS and SCoT markers. J Rad Res Appl Sci. 2020;13(1):61-70. doi: 10.1080/16878507.2019.1697079

26. Brown MA, Petreas MX, Okamoto HS, Mischke TM, Stephens RD. Monitoring of malathion and its impurities and environmental transformation products on surfaces and in air following an aerial application. Environ Sci Technol. 1993;27(2):388-397. doi: 10.1021/ es00039a020.

27. Abd-Rabo FH, Elsalamony H, Sakr SS. Reduction of pesticide residues in Egyptian buffalo milk by some processing treatments. Int J Dairy Sci, 2016; 11, 75-80.

28. FAO/WHO. Joint FAO/WHO food standards programme: Codex alimentarius commission. Pesticide Residues in Food, 2008; Volume, 11, Rome, Italy.

29. Thabit T, El-Naggar MA. Malathion degradation by soil isolated bacteria and detection of degradation products by GC-MS. Int J Environ Sci. 2013;3(5):14671476. doi: 10.6088/ijes.20130305000177

30. Singh AK, Seth PK. Degradation of malathion by microorganisms isolated from industrial effluents. Bull Environ Contam Toxicol. 1989;43(1):28-35. doi: 10.1007/BF01702234

31. Raina R, Sun L. Trace level determination of selected organophosphorus pesticides and their degradation products in environmental air samples by liquid chromatography-positive ion electrospray tandem mass spectrometry. Environ Sci Health Part B. 2008;43(4):323-332. doi: 10.1080/03601230801941667

32. Chu $Y-H, Y u X-X$, Jin $X$, et al. Purification and characterization of alkaline phosphatase from lactic acid bacteria. RSC Advances. 2019;9(1):354-360. doi: 10.1039/C8RA08921C 